\title{
Improvement of memory deficits via acetylcholinesterase inhibitory activity of Nepeta nuda ssp. nuda essential oil in rats
}

\author{
Emel Akbaba ${ }^{1, *}$, Eyup Bagci', Lucian Hritcu², Calin Maniu ${ }^{2}$ \\ ${ }^{\prime}$ Dept. of Biology, Faculty of Science, Firat University, Elazig, Turkey \\ ${ }^{2}$ Dept. of Biology, Alexandru Ioan Cuza University of Iasi, Iasi, Romania \\ *Corresponding authoreakbaba@firat.edu.tr
}

\begin{abstract}
Nepeta L. (Lamiaceae) species are belonging to aromatic and medicinal plants. Many biological activities of Nepeta species have been reported. In this study, memory-enhancing activities of Nepeta nuda ssp. nuda essential oil was aimed to be evaluated in laboratory rats treated with scopolamine. GC-MS/GC-FID system was used to identify oil composition. Memory performances of the rats were tested using Y-maze and radial-arm maze. Acetylcholinesterase enzyme activity and molecular docking analysis were also performed in this study. In total, 44 different compounds were identified in Nepeta nuda ssp. nuda essential oil. Trans-cis nepetalactone was showed to be the most abundant constituent in the oil. In the Y-maze test, the oil improved the performances of the animals on spontaneous alternation. Besides, in the radial-arm maze test, the oil improved working and reference memory significantly impaired in the rats subjected to scopolamine. The oil also showed acetylcholinesterase inhibitory activity in vitro. The molecular docking method, in the meantime, revealed that some of the compounds in the oil could interact with the acetylcholinesterase enzyme, theoretically. Nepeta nuda ssp. nuda essential oil improved spatial memory of scopolamine-induced rats. Neuroprotective effects of the oil are probably related to the anti-cholinesterase activity of the oil. Therefore, Nepeta nuda ssp. nuda essential oil could be used as a complementary therapy to improve memory in Alzheimer's and related diseases.
\end{abstract}

Keywords: Essential oil; memory; Nepeta nuda; scopolamine; Y-maze.

\section{Introduction}

Alzheimer's disease (AD), the most common type of dementia, is characterized by considerable cognitive impairment caused by neuronal brain damage. The number of $\mathrm{AD}$ patients is predicted to be 135 million worldwide by 2050 (Guo et al., 2016) that causes frustration as it is a nocure disease. The main pathological features of the disease are an aggregation of amyloid plaques with neurofibrillary tangles formed in the brain. Many other conditions like oxidative stress and inflammation are also noted in AD patients (Imam et al., 2016). The main factors causing the disease are not known. However, it is clear that AD is a nonstop disease; therefore, the patient's death is inevitable (Chan et al., 2016). Many treatment treatment strategies have been developed for $\mathrm{AD}$ so far; however, the progression of the disease could not be stopped (Zhao et al., 2016). Furthermore, AD is a disease leading huge implications to the family members who may also experience mental problems (Ikeda et al., 2015).

Cognitive impairments, including memory deterioration, are the prominent clinical symptoms of the disorder. On the other hand, behavioral symptoms of $\mathrm{AD}$ are observed in approximately $75-90 \%$ of $\mathrm{AD}$ patients. Therefore, serious consideration should also be given to non-cognitive symptoms (Kandiah et al., 2014). Apathy, aberrant motor activity, dysphoria, depression, and anxiety were a few of the most frequent 
symptoms reported in AD patients (Rea et al., 2014; Piccininni et al., 2005).

Scopolamine is an antagonist for muscarinic receptors. Studies have shown that cognitive problems, including a memory decline, arise by scopolamine in animals and humans (Lin et al., 2016). Therefore, a scopolamine-mediated animal model of dementia has been applied to screen drugs that may possess neuroprotective properties (Ghumatkar et al., 2015).

Presently, available anti-AD drugs possess several side effects. Therefore, novel medications based on natural substances or products with neuroprotective properties without possessing significant side effects are required urgently (Habibyar et al., 2016).

Acetylcholine (ACh) is a wellcharacterized neurotransmitter. The enzyme acetylcholinesterase (AChE), on the other hand, breaks down $\mathrm{ACh}$ functioning in cholinergic neurotransmission. Anticholinesterase medications (rivastigmine, galanthamine, and donepezil) have been used in AD treatment (Vilela et al., 2019). AChE inhibitory activity of many compounds so far has been screened. Molecular docking studies are widely incorporated in the drug discovery process in order to save time and money. Basically, docking studies are applied to evaluate whether two molecules interact and form a stable complex. In that case, predicting the correct orientation of the molecules in the complex is also performed via molecular docking (Gupta et al., 2018).

Nepeta L. (Lamiaceae) incorporates nearly 250 species distributed in many parts of the World, mainly in central and south Europe, Asia, and the Middle East. 33 Nepeta species are identified in Turkey (Kilic et al., 2011). Nepeta nuda is a widespread species of the genus divided into four subspecies, while Nepeta nuda ssp. nuda being one of them. Nepeta species are also within medicinal plants due to many biological activities, including antispasmodic, expectorant, diuretic, antitussive, antiasthmatic, and sedative properties (Gormez et al., 2013). Furthermore, Nepeta species have been reported to have anxiolytic, antioxidant, antibacterial, antifungal, antiviral, antinociceptive, analgesic, and anti-inflammatory activities. Several Nepeta species are also known to be applied in local places of Turkey as herbal teas to treat gastric disorders (Formisano et al., 2011).

According to our extensive literature survey, there is no study on the effects of Nepeta nuda ssp. nuda essential oil on memory deficits in scopolamine model of AD. In this study, neuroprotective activities of the oil were evaluated.

\section{Materials and Methods}

\subsection{Plant Materials and Distillation of Essential Oil}

The plant species used in this study is $N$. nuda ssp. nuda. The plant materials were harvested with leaves and flowers in Bingol, Turkey. The roots were kindly removed. Only aerial parts were used for essential oil distillation, which was dried away from sunlight to keep the essential oil. A sample of the species was stored in Firat University Herbarium (FUH), in which the species were identified. When the plant materials were dried correctly, they were placed in a flask containing enough water for hydrodistillation. The essential oil was obtained using Clevenger-type apparatus $(0.7 \%$ yield $)$ in 3 hours, and the oil was stored at $4^{\circ} \mathrm{C}$ until characterized.

\subsection{Gas Chromatography (GC-FID) Analysis}

GC-FID/GC-MS systems characterized Nepeta nuda sp. nuda oil. GC- FID analysis was performed using the Hewlett PackardAgilent 5973N GC-MS system with 6890 GC. The system was supplied with a flame ionization detector (FID). The conditions of the system were as follows: The carrier gas used in the system was helium; the column was HP-5 MS, $30 \mathrm{~m} \times 0.25 \mathrm{~mm}$ i.d., $0.25 \mu \mathrm{m}$ film thickness; the oil was diluted 100 times 
in n-hexane; $1.0 \mu \mathrm{L}$ oil was injected in the splitless mode; the temperature of injector was $250^{\circ} \mathrm{C}$, and the flow rate was $1.3 \mathrm{~mL} /$ $\min$. The analysis procedure was as follows: Oven temperature of GC was kept for 2 minutes at $70^{\circ} \mathrm{C}$ and gradually increased to $150^{\circ} \mathrm{C}$ at a rate of $10{ }^{\circ} \mathrm{C} / \mathrm{min}$. After that, the temperature was kept constant at $150^{\circ} \mathrm{C}$ for $15 \mathrm{~min}$ and then increased again to $240^{\circ} \mathrm{C}$ at a rate of $5^{\circ} \mathrm{C} / \mathrm{min}$. The composition of the essential oil in percentages was obtained from GC-FID peaks without correction factors.

\subsection{Gas Chromatography (GC-MS) Analysis}

The same column was used for GC-MS analysis. The conditions were also the same with GC-FID and GC-MS. Retention indices (RI) were calculated using n-alkanes (C8-40) as reference. MS were taken at $70 \mathrm{eV}$ and a mass range of 35-425. The compounds were identified by comparing their RIs and mass spectra obtained from two libraries (Wiley 7 and Nist 98).

\subsection{Animals and Experimental Groups}

In this study, 28 female Wistar rats were used (250-300 grams). Water and food were provided free to all animals (ad libitum) in the facility in which temperature and light were also controlled $\left(22^{\circ} \mathrm{C}, 12\right.$-h cycle). The animals were handled gently with respect to the principles of animal welfare. The local ethical committee of Firat University approved this study (Permit Number: 04.11.2015/180). The animals were divided into four following groups (7 animals per group): 1. Control animals received $0.9 \%$ saline. 2. Scopolamine (Sco)- alone-treated animals received $1.5 \mathrm{mg} / \mathrm{kg}$ Sco in $0.9 \%$ saline, as a negative control. 3. Scopolaminetreated animals received $1 \% \quad N$. nuda ssp. nuda essential oil (Sco+NPT1\%). 4. Scopolamine-treated animals received 3\% $N$. nuda ssp. nuda essential oil (Sco+NPT3\%).
2.5.Inhalation apparatus and drug administration

The animals were treated with $N$. nuda ssp. nuda essential oil by inhalation. The inhalation procedure was performed in a Plexiglass chamber $(50 \times 40 \times 28 \mathrm{~cm})$. At first, the essential oil was diluted with Tween $20(1 \%)$ and exposed to the rats $(200 \mu \mathrm{l})$. An electronic vaporizer (Oregon Scientific WS113) was used to administer essential oils (Gradinariu et al., 2014). The testing animals were exposed to essential oil vapors daily for 21 days (15 minutes/day). After one group finished the session, the chamber was cleaned properly with ethanol $(10 \%)$. Scopolamine hydrobromide was dissolved in $0.9 \% \mathrm{NaCl}$, and the rats were subjected to scopolamine $(1.5 \mathrm{mg} / \mathrm{kg})$ by intraperitoneal (i.p.) injection. 30 minutes after injection, the rats were tested behaviorally. All chemicals were purchased from Sigma-Aldrich, Germany.

\subsection{Y-maze test}

Y-maze test was applied to evaluate shortterm memory in this study. This Y-shaped maze has 3 arms and a central area. We named these arms $\mathrm{A}, \mathrm{B}$, and $\mathrm{C}(35 \mathrm{~cm}$ long and $10 \mathrm{~cm}$ wide) and put the maze $25 \mathrm{~cm}$ high. At the beginning of the session, each rat was placed in the central area facing arm A so that every rat was oriented in the same way. The rats could move freely in the maze for 8 minutes. At the same time, the arms which rats were entered were noted carefully. When 4 paws of a rat were not inside the arm, this was not counted as an entrance. After 8 minutes, the rats were handled and moved out of the maze, and the maze was cleaned with ethanol $(10 \%)$ and prepared for the next animal. When the rat moved all three arms consecutively (ABC or ACB or $\mathrm{CAB}$ etc.), this was counted as correct alternation. The calculation of spontaneous alternation percentage was as follows: (the number of correct alternations/ total number of entrances minus 2) x100. 


\subsection{Radial arm-maze test}

The radial arm maze had 8 equal arms (48 $\mathrm{cm}$ long x $12 \mathrm{~cm}$ wide) and a circular area in the center. The length of one arm extending from the center was $32 \mathrm{~cm}$. The arms had no difference between each other, and there was a small cup at the ends of the arms. The maze was put $50 \mathrm{~cm}$ high, surrounded by many visual cues away from the maze. Before this test, the rats were fed a restricted diet to lose $15 \%$ of the weight to lead them to search for food. This test consisted of pretraining and testing sessions. Pre-training sessions were last for 4 days. These days, the rats were allowed to search the maze for 5 minutes and eat the food pellets put in the maze. On the first day of pre-training, the food pellets were available throughout the maze, while gradually the number of pellets was reduced, and on the final day, only one pellet was placed in the food cup. Therefore, the animals could learn to search for food in a limited time in the pre-training sessions. The testing sessions, on the other hand, were last for 7 days long. This time only 5 arms were baited (number 1,2,4,5 and 7). The other arms were not baited, consisting of empty cups. Within 5 minutes, the rats were allowed to search for the baited arms. Working memory error was accounted as the entrance of the rat in a baited arm but previously entered. Reference memory error was accounted as the entrance in an unbaited arm. When the rats entered baited arms and consumed all the pellets within the time, they were removed from the maze. After each trial, the maze was cleaned with $10 \%$ ethanol and prepared for the next rat (Hritcu et al., 2014).

\subsection{Hippocampal AChE Activity}

After the tests, all rats were anesthetized and then decapitated. The hippocampi were removed from the whole brain and immediately washed with cold $\left(+4^{\circ} \mathrm{C}\right)$ potassium phosphate buffer and dried with drying paper. The samples were then quickly moved to a liquid nitrogen tank. Until analysis time, they were kept at $-80^{\circ} \mathrm{C}$.

Before the analysis, the samples were weighed and homogenized (Kema Keur, model pro 200, Pro Sci. Inc., USA) in $0.1 \mathrm{M}$ cold potassium phosphate buffer $(\mathrm{pH}$ : 7.4, 1:9, w: v) for 2 minutes at $16000 \mathrm{rpm}$. These homogenates were then centrifuged at $+4^{\circ} \mathrm{C}$, for 30 minutes at $16000 \mathrm{rpm}$ prior to supernatant removal. AChE activity of the homogenates was determined by the Elisa kit (Rel Assay, MEGA group) according to the kit protocol.

\subsection{Molecular Docking studies}

For docking studies, Protein Data Bank (PDB) was used to obtain human AChE complex (PDB ID: 4M0F) (Cheung et al., 2013) (Berman et al., 2000). The molecular docking was performed via VEGA ZZ (Pedretti et al., 2004) in conjunction with Nanoscale Molecular Dynamics (NAMD) (Phillips et al., 2005) and AutoDock4. First, the PDB structure of the enzyme was refined by normalizing the coordinates to translate the protein at the origin of the Cartesian axis, then the hydrogens were added. After that, it was manually remaining protonation problems were solved. To optimize the crystalline structure of the complex, firstly, was used the PDB- REDO server. PDB-REDO is a procedure to optimize crystallographic structure models (Joosten et al., 2014). Finally, NAMD was used to carry out an energy minimization procedure.

AChE active site has a gorge possessing a catalytic site that contains a catalytic triad (Sussman et al., 1991). In human AChE, the catalytic triad constitutes H447, E334, and S203. Another site beyond Y337 contains many aromatic side chains facing the entrance of the gorge. These two binding sites were shown to be targeted and interacted by inhibitors (Rosenberry et al., 2008) In this study, AChE and Territrem B complex was used. The structure of Territrem B was taken from the PubChem database and removed from the complex (Bolton et al., 2008). 
Water molecules were eliminated from the AChE structure; AMBER atom types were assigned, atom charges were fixed, apolar hydrogen atoms were removed, and transformed the molecule to PDBQT format. PyMOL was used to process the docking images, and noncovalent interactions were evaluated by Protein-Ligand Interaction Profiler (PLIP) (Salentin et al., 2015).

\subsection{Statistical analysis}

For statistical analysis, ANOVA (One-way analysis of variance) was used, incorporated into GraphPad Prism 6. In addition, Tukey's post hoc multiple comparisons follow-up test was conducted. Furthermore, only in radial arm maze, to identify differences in groups and time, repeated measure ANOVA was used on the number of working memory and reference memory errors. The outcomes were represented as mean \pm standard error of the mean (S.E.M). $\mathrm{P} \leq 0.05$ was considered as the significance level.

\section{Results}

3.1. Chemical composition of the Nepeta nuda ssp. nuda essential oil

The essential oil components of $N$. nuda ssp. nuda were assessed by GC-MS/GCFID system. The analysis revealed that 44 compounds in the oil constituted $90.1 \%$ of the total oil (Table 1). According to the analysis, the majority of the oil was composed of $4 \mathrm{a} \alpha, 7 \alpha, 7 \mathrm{a} \beta$-nepetalactone $\quad(50.0 \%)$. Other compounds including caryophyllene oxide (10.9\%), (+) spathulenol (3.3\%), Trans- $\beta$-caryophyllene $(2.7 \%), 4 a \alpha, 7 \alpha, 7 \mathrm{a} \alpha-$ nepetalactone $(2.6 \%)$, and germacrene-D (2.4 $\%)$ were found abundantly in the oil. These compounds constitute $71.9 \%$ of the total oil. Nepetalactones are monoterpenehydrocarbons, while caryophyllene oxide, spathulenol, trans$\beta$-caryophyllene, and germacrene-D belong to sesquiterpene hydrocarbons and derivatives.

\subsection{Alternation Behavior in Y-maze task}

The effect of $N$. nuda ssp. nuda essential oil on memory was illustrated in Figure. 1 as alternation behavior. In this task, spontaneous alternation percentage revealed significant differences between all groups (ANOVA, $F(3,16)=6.87, p<0.005)$. In the Y-maze task, as compared to the control group, scopolamine application decreased the percentage of spontaneous alternation as expected $(p<0.005)$. Significant differences between Sco vs Sco+NPT 1\% $(p<0.05)$ and Sco vs Sco+NPT 3\% $(\mathrm{p}<0.05)$ were obtained via Tukey's post hoc test. It is clearly understood in the graph that administration of both doses of $N$. nuda ssp. nuda essential oil caused a significant increase in spontaneous alternation $\%$ in scopolamine-induced rats.

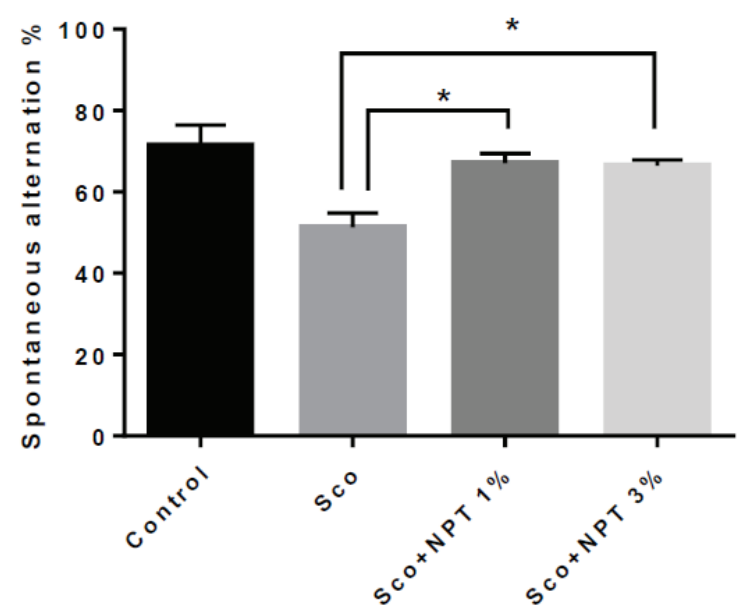

Fig. 1. Effects of inhaled Nepeta nuda ssp. nuda essential oil (Sco+NPT 1\% and Sco+NPT 3\%) in the Y-maze on spontaneous alternation percentage.

3.3. Memory evaluation in the Radial arm maze Task

Scopolamine-treated rats were further evaluated in terms of spatial memory by radial arm maze test. For working memory errors, one-way ANOVA revealed significant overall differences between groups $[\mathrm{F}(3,24)$ $=3.07, \mathrm{p}<0.05]$.

Tukey's post hoc analysis showed significant differences between control vs. 
Sco $(\mathrm{p}<0.05)$ and Sco vs. Sco + NPT3\% $(p<0.05)$ in working memory errors. In the meantime, repeated-measures ANOVA revealed a significant time and group difference $(F(18,112)=3.55, p<0.0001)$ (Figure. 2a).

For reference memory errors, oneway ANOVA revealed significant overall differences between groups $[\mathrm{F}(3,24)=12.14$, $\mathrm{p}<0.0001]$. Tukey's post hoc analysis showed significant differences between control vs. Sco $(p<001)$, Sco vs. Sco+NPT1\% $(p<0.0001)$, and Sco vs. Sco+NPT3\% $(p<0.0001)$.
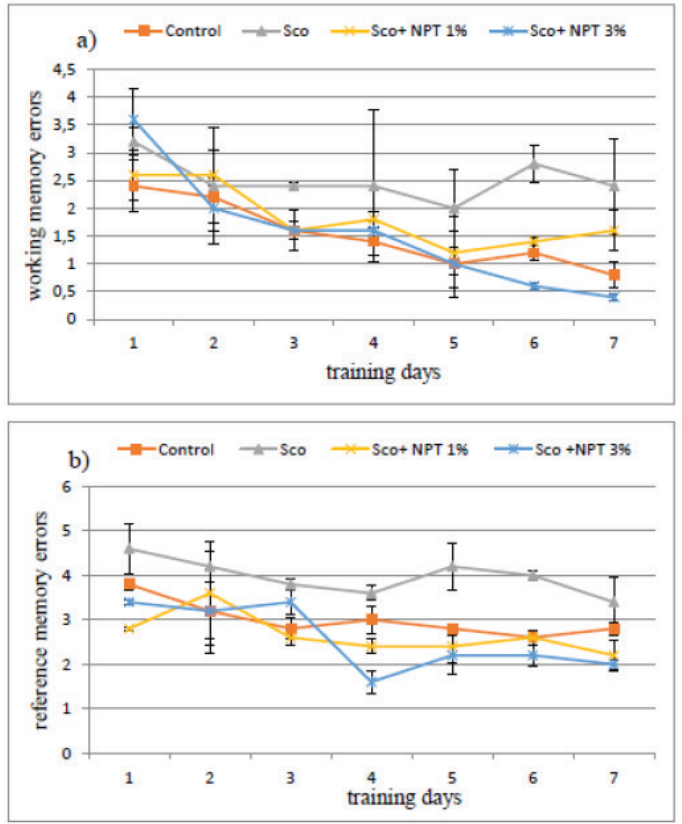

Fig. 2. Effects of inhaled Nepeta nuda ssp. nuda essential oil (Sco+NPT 1\% and Sco+NPT $3 \%$ ) on the (a) working memory errors and (b) the reference memory errors in the radial arm-maze.

Repeated-measures ANOVA revealed a significant time difference $(\mathrm{F}(6,112)=2.10$, $\mathrm{p}<0.05)$ and group difference $(\mathrm{F}(3,112)$ $=14.94, \mathrm{p}<0.0001)$ (Figure 2(b)).

3.4. AChE inhibitory activity of Nepeta nuda ssp. nuda Essential oil

$\mathrm{AChE}$ activity was determined in the hippocampal homogenates of the rats (Figure. 3). One-way ANOVA revealed significant differences between all groups $[F(3,20)$ $=23.56, \mathrm{p}<0.0005]$. Additionally, Tukey's
Table 1. Constituents of Nepeta nuda ssp. nuda essential oil.

\begin{tabular}{|c|c|c|c|}
\hline NO & Compounds & RI & $\%$ \\
\hline 1 & 1-Octen-3-ol & 1056 & 0.3 \\
\hline 2 & 1-Acetylcyclohexene & 1092 & 0.1 \\
\hline 3 & Eucalyptol & 1097 & 1.8 \\
\hline 4 & Linalool & 1147 & 0.1 \\
\hline 5 & Norinone & 1175 & 0.2 \\
\hline 6 & Trans-pinocarveol & 1177 & 0.1 \\
\hline 7 & 4-Terpineol & 1204 & 0.2 \\
\hline 8 & Methyl salicylate & 1212 & 0.1 \\
\hline 9 & $m$-Mentha 1,8 diene & 1215 & 0.3 \\
\hline 10 & $\begin{array}{l}\text { Cis-3-hexenyl } \\
\text { isovalerate }\end{array}$ & 1241 & 0.1 \\
\hline 11 & $\begin{array}{l}\text { 4a } \alpha, 7 \alpha, 7 \mathbf{a} \alpha- \\
\text { Nepetalactone }\end{array}$ & 1348 & 2.6 \\
\hline 12 & $\alpha$-Cubebene & 1358 & 0.4 \\
\hline 13 & $\beta$-Bourbonene & 1365 & 1.9 \\
\hline 14 & $\begin{array}{l}\text { 4a } \alpha, 7 \alpha, 7 \mathbf{a} \beta- \\
\text { Nepetalactone }\end{array}$ & 1380 & 50.0 \\
\hline 15 & $\alpha$-Gurjunene & 1384 & 0.4 \\
\hline 16 & Trans- $\beta$-caryophyllene & 1393 & 2.7 \\
\hline 17 & $\beta$-Cubebene & 1399 & 0.2 \\
\hline 18 & (Z) $\beta$-Farnesene & 1414 & 0.2 \\
\hline 19 & $\alpha$-Humulene & 1417 & 0.8 \\
\hline 20 & Aromadendrene & 1420 & 0.3 \\
\hline 21 & $\begin{array}{l}(+) \text { Epibicyclosesqui } \\
\text { phellandrene }\end{array}$ & 1426 & 0.1 \\
\hline 22 & $\gamma$-Cadinene & 1430 & 0.1 \\
\hline 23 & Germacrene D & 1434 & 2.4 \\
\hline 24 & Germacrene B & 1444 & 0.2 \\
\hline 25 & $\beta$-Bisabolene & 1451 & 0.8 \\
\hline 26 & $\alpha$-Amorphene & 1455 & 0.2 \\
\hline 27 & 1-Endobourbonalol & 1457 & 0.5 \\
\hline 28 & $\alpha$-Calamenene & 1459 & 0.2 \\
\hline 29 & $\beta$-Sesquiphellandrene & 1461 & 0.3 \\
\hline 30 & Elemol & 1477 & 0.3 \\
\hline 31 & $\alpha$-Bergomotene & 1479 & 0.9 \\
\hline 32 & 1,5 epoxysalvial $4(14)$ ene & 1489 & 0.5 \\
\hline 33 & Palustrol & 1490 & 0.8 \\
\hline 34 & (+)Spathulenol & 1496 & 3.3 \\
\hline 35 & Caryophyllene oxide & 1499 & 10.9 \\
\hline 36 & $\gamma$-Gurjunene & 1504 & 0.5 \\
\hline 37 & Ledol & 1511 & 1.9 \\
\hline 38 & Nor-copaanone & 1520 & 0.5 \\
\hline 39 & Caryophylladienol II & 1528 & 0.3 \\
\hline 40 & $\alpha$-Cadinol & 1538 & 1.5 \\
\hline 41 & $\begin{array}{l}\text { Isoaromadendrene } \\
\text { epoxide }\end{array}$ & 1573 & 0.4 \\
\hline 42 & Perhydrofarnesyl acetone & 1630 & 0.3 \\
\hline 43 & n-hexadecanoic acid & 1691 & 0.2 \\
\hline 44 & $\begin{array}{l}\text { Phytol } \\
\text { TOTAL }\end{array}$ & 1791 & $\begin{array}{l}0.2 \\
\mathbf{9 0 . 1}\end{array}$ \\
\hline
\end{tabular}


post hoc analysis showed significant differences between Sco vs. Sco+NPT $1 \%(\mathrm{p}<0.0005)$ and Sco vs. Sco+NPT 3\% $(\mathrm{p}<0.005)$.

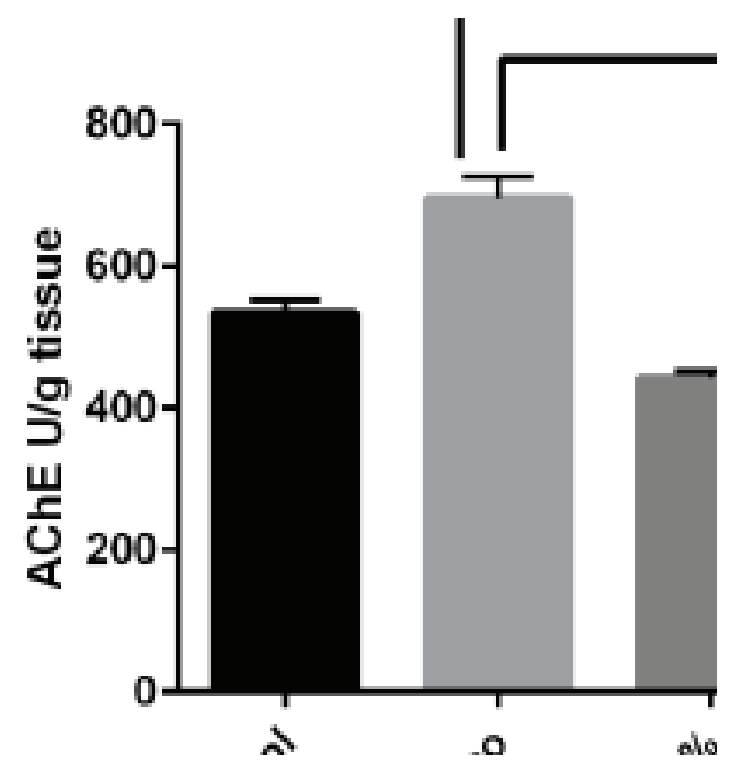

Fig. 3. Acetylcholinesterase inhibitory effect of Nepeta nuda ssp. nuda essential oil (NPT $1 \%$ and NPT 3\%).

\subsection{Molecular docking analysis}

The interaction of the compounds in the essential oil with the AChE enzyme was carried out by molecular docking. The best docking score was received by perhydro farnesyl acetone, which was not a major component of the oil. The Binding free energy of perhydro farnesyl acetone was found as -8.60 , while the inhibition constant was $0.495 \mu \mathrm{M}$. In the meantime, the major component of the oil, transcis-nepetalactone, gave a good docking profile. The Binding free energy of transcis-nepetalactone was found as -6.55 , while the inhibition constant was $15.8 \mu \mathrm{M}$. The positions of perhydro farnesyl acetone and trans-cis-nepetalactone interacted with the AChE enzyme are shown in Figure. 4. The interaction of territrem-B with $\mathrm{AChE}$ is also shown as a reference.

\section{Discussion}

The location, geomorphological structure, and the effects of diverse climate types are the major factors determining Turkey's rich

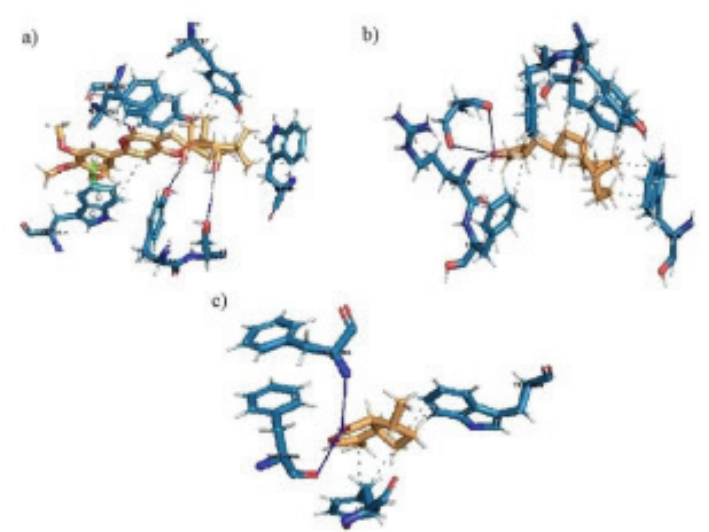

Fig. 4. The interaction positions of the molecules within the AChE enzyme: a) territrem-B, b) perhydro farnesyl acetone, and c) trans-cis-nepetalactone. Hydrogen bonds were showed as (_ $)$, hydrophobic interactions were showed as (- - -), and $\pi$-stacking were shown as (- - ).

flora. In the rural areas of Turkey, a relatively higher number of people apply plants for medical purposes (Paksoy et al., 2016). Not only in Turkey, in almost every part of the World, but people also developed cures based on herbs. In traditional or convenient medicine, between 50-70 thousand plant species are used worldwide (Güler et al., 2015).

Plants provide a wide range of sources to produce novel medications for the treatment of various conditions. Among plant products, essential oils present a complex chemical composition synthesized by plants as secondary metabolites. Many biological activities of essential oils have been reported, including antioxidant and anticholinesterase effects. However, the unique set of chemicals in the oil can be easily affected by environmental or other factors; this situation, therefore, could limit the verification of the experimental results (Matos et al., 2019).

Nepeta L. has a cosmopolitan distribution in the World (Sarikurkcu et al., 2019). Nepeta species are important as medicinal and ornamental plants possessing pleasant appearance and odor. Reported pharmacological activities of Nepeta species include antioxidant and sedative activities (Salehi et al., 2018). 
Previously, Nepeta angustifolia extract was reported to improve renal function in diabetic rats via antioxidant activity (Huang et al., 2020). Nepeta paulsenii extract, on the other hand, was showed to ameliorate testicular damage and improve antioxidative enzyme activity (Samad et al., 2020).

Plant products, especially essential oils, have been evaluated for pest and insect control (Manzoor et al., 2016). Several essential oils and plant extracts have been reported to be used as pesticides or insecticides (Arshad et al., 2019), including Nepeta species (Salehi et al., 2018). Insect-repellant and insecticidal effects are generally related to $\mathrm{AChE}$ inhibition. Therefore, we hypothesized that our essential oil in this study could also have anti-cholinesterase activity, which could improve memory functions in laboratory animals.

In the present study, memory-improving effects of Nepeta nuda ssp. nuda essential oil inhalation was revealed in scopolamineinduced rats. The oil was characterized by GC-MS/GC-FID system. 44 different compounds were identified in total. Transcis nepetalactone (monoterpene) was found as the major compound, followed by caryophyllene oxide (sesquiterpene). These compounds could be responsible for the biological effects of the oil in our study.

Essential oil compositions of other species and subspecies of Nepeta were reported before. The major compounds of Nepeta nuda ssp. glandulifera essential oil was reported as geijerene (61.1\%) and neointermedeol $(6.1 \%)$, classified as terpenoids. On the other hand, the major compounds of Nepeta cadmea essential oil were showed as $4 \mathrm{a} \beta, 7 \alpha, 7 \mathrm{a} \beta$-nepetalactone (70.9\%), and $\beta$-caryophyllene (6.3\%), which is in parallel with our results (Sarikurkcu et al., 2018). In another study, nepetalactone was reported to be the dominant constituent followed by $4 a \alpha, 7 \alpha, 7 \mathrm{a} \alpha$-nepetalactone, $\beta$-caryophyllene, and caryophyllene oxide in Nepeta cataria and Nepeta nuda essential oils (Baranauskienè et al., 2019). It is clear that nepetalactones are found as abundant chemicals in the essential oil of Nepeta species.

In this study, the effects of Nepeta nuda ssp. nuda essential oil on the central nervous system, especially memory, was evaluated. In a clinical study, a combination of Melissa officinalis and Nepeta menthoides extract was reported to be effective on depression and anxiety in insomniac patients (Ranjbar et al., 2018). Besides, interesting behavioral effects of Nepeta cataria (catnip) on cats are well-known. The nepetalactones constitute in Nepeta cataria essential oil were reported to produce playful behavior in cats such as scratching, licking, pawing, and head shaking (Luz et al., 2017). Nepeta menthoides extract, on the other hand, was reported to prevent morphine-dependent and tolerance in laboratory animals suggesting a unique product for the patients who have to receive pain killers frequently (Rahmati and Beik, 2017). Therefore, these studies suggest the effects of Nepeta constituents in the brain.

Two well-characterized tests evaluated memory consolidation in this study: the Y-maze test and radial arm maze test. Y- maze task is based on intrinsic rodent behavior of exploring a novel environment, and also spatial memory of the awareness regarding visited arms and the new arm of the maze (Jung et al., 2008). However, radial arm maze is used to assess spatial working and reference memories in laboratory animals (Levin, 2015).

In the $\mathrm{Y}$ maze test, scopolamine injection caused a significant decrease in the spontaneous alternation percentage. However, the spontaneous alternation behavior was significantly improved in the rats subjected to both doses of $N$. nuda ssp. nuda essential oil (NPT1\% and NPT3\%). These results imply that spatial working memory acquisition is increased by inhalation of $N$. nuda ssp. nuda essential oil (NPT1\% and NPT3\%) in scopolaminetreated rats. However, no such difference was observed between Sco+NPT1\% and 
Sco+NPT3\% groups on spontaneous alternation percentage in the Y-maze task.

This study clearly demonstrated that scopolamine impaired spatial memory in the radial arm maze task. Both doses of $N$. nuda ssp significantly reduced the error number of working memory and reference memory. nuda essential oil (NPT1\% and NPT3\%) in the scopolamine administered rats. These findings suggest that inhalation of $N$. nuda ssp. nuda essential oil affects spatial working and reference memory.

There is accumulating evidence that sex differences could affect behavioral scores from minor to moderate levels in laboratory tasks (Song et al., 2018) (Wiersielis et al., 2019). Therefore, generally, only male or female rodents are used in behavioral studies. In this study, we used only female rats to eliminate any discrepancies.

$\mathrm{AChE}$ is an enzyme hydrolyzing the neurotransmitter ACh. AChE was first isolated from Pacific electric ray, and its 3D structure was identified in 1991. Low levels of $\mathrm{ACh}$ are linked to $\mathrm{AD}$ and related diseases. Inhibition of the AChE enzyme by specific inhibitor compounds is the therapeutic procedure in managing AD. Therefore, intensive studies on AChE to search novel AChE inhibitors have been carried out (Khan et al., 2018). Especially after introducing computer-based methods for drug-design, the number of studies on anti-cholinesterase profile of plant products have been elevated. The molecular docking technique is a relatively useful alternative to contribute to the studies of pharmacological activities of compounds since it is a time and money-saving method. It is used to predict the orientation of a molecule bound to a protein. This molecule-protein complex must form a stable coplex.

N. nuda ssp. nuda essential oil inhalation also decreased AChE activity in the hippocampus of the rats treated with scopolamine. Furthermore, molecular docking analysis revealed good docking profiles of the chemical compounds in the oil. The interaction of compounds such as perhydro farnesyl acetone and trans-cisnepetalactone with the AChE enzyme is shown. Therefore, the memory-enhancing effects of the oil could be related to cholinesterase inhibitory properties.

\section{Conclusion}

In this study, Nepeta nuda ssp. nuda essential oil improved memory performances of laboratory rats treated with scopolamine. The essential oil also inhibited the AChE enzyme. Furthermore, theoretically, the binding orientation of transcis-nepetalactone and perhydro farnesyl acetone to AChE was showed by molecular docking. Therefore, memory enhancing activities of Nepeta nuda ssp. nuda essential oil could be related to the anti-cholinesterase activity. Nepeta nuda ssp. nuda essential oil could be used against neurological diseases such as Alzheimer's disease.

\section{ACKNOWLEDGEMENTS}

This study was funded by Firat University Scientific Research Projects Unit, Turkey (FF.15.18).

\section{References}

Arshad, M.; Ullah, M.I.; Afzal, M.; Khalid, S.; Raza, A.B.M. (2019). Evaluation of plant extracts for the management of citrus leafminer, Phyllocnistis citrella (Lepidoptera : Gracillariidae). Kuwait Journal of Science, 46 (1): 58-67.

Baranauskienè, R.; Bendžiuvienè, V.; Ragažinskiené, O.; Rimantas, P. (2019). Essential oil composition of five Nepeta species cultivated in Lithuania and evaluation of their bioactivities, toxicity and antioxidant potential of hydrodistillation residues. Food and Chemical Toxicology, 129: 269-280.

Berman, H.M.; Westbrook, J.; Feng, Z.; Gilliland, G.; Bhat, T.N. et al. (2000). The Protein Data Bank. Nucleic Acids Research, 28 (1): 235-242. 
Bolton, E.E.; Wang, Y.; Thiessen, P.A.; Bryant, S.H. (2008). PubChem: Integrated Platform of Small Molecules and Biological Activities. Annual Reports in Computational Chemistry, 4: 217-241.

Chan, H.L.; Li, H.; Lui, L.M. (2016). Quasi-conformal statistical shape analysis of hippocampal surfaces for Alzheimer's disease analysis. Neurocomputing, 175: 177-187.

Cheung, J.; Gary, E.N.; Shiomi, K.; Rosenberry, T.L. (2013). Structures of Human Acetylcholinesterase Bound to Dihydrotanshinone I and Territrem B Show Peripheral Site Flexibility. ACS Medicinal Chemistry Letters, 4 (11): 1091-1096.

Formisano, C.; Rigano, D.; Senatore, F. (2011). Chemical Constituents and Biological Activities of Nepeta Species. Chemistry \& Biodiversity, 8 (10): 17831818.

Ghumatkar, P.J.; Patil, S.P.; Jain, P.D.; Tambe,R.M.; Sathaye,S.(2015).Nootropic, neuroprotective and neurotrophic effects of phloretin in scopolamine-induced amnesia in mice. Pharmacology, biochemistry, and behavior, 135: 182-91.

Gormez, A.; Bozari, S.; Yanmis, D.; Gulluce, M.; Agar, G. et al. (2013) Antibacterial activity and chemical composition of essential oil obtained from Nepeta nuda against phytopathogenic bacteria. Journal of Essential Oil Research, 25 (2): 149-153.

Gradinariu, V.; Cioanca, O.; Hritcu, L.; Gille, E.; Trifan, A. et al. (2014). Comparative efficacy of Ocimum sanctum and Ocimum basilicum volatile oils against amyloid-beta (1-42)-induced anxiety and depression in laboratory rats. Phytochem Rev, 14: 567-575.
Güler, B.; Manav, E.; Uğurlu, E. (2015). Medicinal plants used by traditional healers in Bozüyük (Bilecik-Turkey). Journal of ethnopharmacology, 173: 39-47.

Guo, C.; Shen, J.; Meng, Z.; Yang, X.; Li, F. (2016). Neuroprotective effects of polygalacic acid on scopolamine-induced memory deficits in mice. Phytomedicine : international journal of phytotherapy and phytopharmacology, 23 (2): 149-55.

Gupta, M.; Sharma, R.; Kumar, A. (2018). Docking techniques in pharmacology: How much promising? Computational Biology and Chemistry, 76: 210-217.

Habibyar, A.F.; Sharma, N.; Khurana, $N$. (2016). PASS assisted prediction and pharmacological evaluation of hesperidin against scopolamine-induced amnesia in mice. European Journal of Pharmacology, 789: 385-394.

Hritcu, L.; Noumedem, J.; Cioanca, O.; Hancianu, M.; Kuete, V. et al. (2014) Methanolic Extract of Piper nigrum Fruits Improves Memory Impairment by Decreasing Brain Oxidative Stress in Amyloid Beta(142) Rat Model of Alzheimer's Disease. Cellular and Molecular Neurobiology, 34 (3): 437-449.

Huang, S.; Tan, M.; Guo, F.; Dong, L.; Liu, Z. et al. (2020). Nepeta angustifolia C. Y. Wu improves renal injury in HFD/ STZ-induced diabetic nephropathy and inhibits oxidative stress-induced apoptosis of mesangial cells. Journal of Ethnopharmacology, 255: 112771.

Ikeda, C.; Terada, S.; Oshima, E.; Hayashi, S.; Okahisa, Y. et al. (2015). Difference in determinants of caregiver burden between amnestic mild cognitive impairment and mild Alzheimer's disease. Psychiatry research, 226 (1): 242-6. 
Imam, A.; Ajao, M.S.; Ajibola, M.I.; Amin, A.; Abdulmajeed, W.I. et al. (2016). Black seed oil ameliorated scopolamineinduced memory dysfunction and corticohippocampal neural alterations in male Wistar rats. Bulletin of Faculty of Pharmacy, Cairo University, 54(1): 49-57.

Joosten, R.P.; Long, F.; Murshudov, G.N.; Perrakis, A. (2014). The PDB REDO server for macromolecular structure model optimization. International Union of Crystallography, 1 (4): 213-220.

Jung, W.R.; Kim, H.G.; Kim, K.L. (2008). Ganglioside GQ1b improves spatial learning and memory of rats as measured by the Y-maze and the Morris water maze tests. Neuroscience letters, 439 (2): 220-5

Kandiah, N.; Chander, R.; Zhang, A.; Yee, C.C. (2014). Cerebral white matter disease is independently associated with BPSD in Alzheimer's disease. Journal of the neurological sciences, 337 (1-2): 162-6.

Khan, H.; Marya, Amin, S.; Kamal, M.A.; Patel, S. (2018). Flavonoids as acetylcholinesterase inhibitors: Current therapeutic standing and future prospects. Biomedicine \& Pharmacotherapy, 101: 860870 .

Kilic, O.; Hayta, S.; Bagci, E. (2011). Chemical Composition of Essential Oil of Nepeta nuda L. subsp nuda (Lamiaceae) from Turkey. Asian Journal Of Chemistry, 23 (6): 2788-2790.

Levin, E.D. (2015). Learning about cognition risk with the radial-arm maze in the developmental neurotoxicology battery. Neurotoxicology and teratology, 52: 88-92.

Lin, J.; Huang, L.; Yu, J.; Xiang, S.; Wang, J. et al. (2016). Fucoxanthin, a Marine Carotenoid, Reverses Scopolamine-
Induced Cognitive Impairments in Mice and Inhibits Acetylcholinesterase in Vitro ( $\mathrm{T}$ Sugawara and T Maoka, eds). Marine Drugs, 14 (4): 67.

Luz, A.; Esp, T.; Canseco-sedano, R. (2017). Active and passive responses to catnip (Nepeta cataria) are affected by age, sex, and early gonadectomy in male and female cats. Behavioural Processes, 142: 110-115.

Manzoor, F.; Zafar, A.; Iqbal, I. (2016). Heterotermesindicola (Wasmann) (Isoptera: Rhinotermitidae) responses to extracts from three different plants. Kuwait Journal of Science, 43 (3): 128-134.

Matos, S.P.; Lucca, L.G.; Koester, L.S. (2019). Essential oils in nanostructured systems: Challenges in preparation and analytical methods. Talanta, 195: 204-214.

Paksoy, M.Y.; Selvi, S.; Savran, A. (2016). Ethnopharmacological survey of medicinal plants in Ulukışla (Niğde-Turkey). Journal of Herbal Medicine, 6 (1): 42-48.

Pedretti, A.; Villa, L.; Vistoli, G. (2004). VEGA - An open platform to develop chemo-bio-informatics applications, using plug-in architecture and script programming. Journal of Computer-Aided Molecular Design, 18 (3): 167-173.

Phillips, J.C.; Braun, R.; Wang, W.; Gumbart, J.; Tajkhorshid, E. et al. (2005). Scalable molecular dynamics with NAMD. Journal of Computational Chemistry, 26 (16): 1781-1802.

Piccininni, M.; Carlo, A.D.; Baldereschi, M.; Zaccara, G.; Inzitari, D. (2005). Behavioral and psychological symptoms in Alzheimer's disease: Frequency and relationship with duration and severityof the disease. Dementia and Geriatric Cognitive Disorders, 19: 276-281. 
Rahmati, B.; Beik, A. (2017). Prevention of morphine dependence and tolerance by Nepeta menthoides was accompanied by attenuation of Nitric Oxide overproduction in male mice. Journal of Ethnopharmacology, 199: 39-5.

Ranjbar, M.; Firoozabadi, A.; Salehi, A.; Ghorbanifar, Z. (2018). Effects of Herbal combination (Melissa officinalis L. and Nepeta menthoides Boiss. \& Buhse) on insomnia severity, anxiety and depression in insomniacs : Randomize placebo-controlled trial. Integrative Medicine Research, 7(4): 328-332.

Rea, R.; Carotenuto, A.; Fasanaro, A.M.; Traini, E.; Amenta, F. (2014). Apathy in Alzheimer's Disease: Any Effective Treatment? 2014: 421385.

Rosenberry, T.L.; Sonoda, L.K.; Dekat, S.E.; Cusack, B.; Johnson, J.L. (2008). Analysis of the reaction of carbachol with acetylcholinesterase with thioflavin $\mathrm{T}$ as a coupled fluorescence reporter. Biochemistry, 47 (49): 13056-13063.

Salehi, B.; Valussi, M.; Jugran, A.K.; Martorell, M.; Ramírez-Alarcón, K. et al. (2018). Nepeta species: From farm to food applications and phytotherapy. Trends in Food Science \& Technology, 80: 104-122.

Salentin, S.; Schreiber, S.; Haupt, V.J.; Adasme, M.F.; Schroeder, M. (2015). PLIP: fully automated protein-ligand interaction profiler. Nucleic Acids Research, 43: W443-W447.

Samad, A.; Umar, M.; Ashraf, A.; Sajid, M.; Imran, M. et al. (2020). Journal of King Saud University-Science Methanolic extract of Nepeta paulsenii as an ameliorative agent against $\mathrm{CCl} 4$ induced testicular damage in male albino rats. Journal of King Saud University - Science, 32 (1): 1168-1174.

Sarikurkcu, C.; Ceylan, O.; Targan, S.; Sanja, Ć. (2018). Chemical composition and biological activities of the essential oils of two endemic Nepeta species. Industrial Crops and Products, 125: 5-8.

Sarikurkcu, C.; Eskici, M.; Karan, A.; Tepe, B. (2019). South African Journal of Botany Phenolic profile, enzyme inhibitory and antioxidant activities of two endemic Nepeta species: Nepeta nuda subsp. glandulifera and $N$. cadmea. South African Journal of Botany, 120: 298-301.

Song, Z.; Kalyani, M.; Becker, J.B. (2018). Sex differences in motivated behaviors in animal models. Current Opinion in Behavioral Sciences, 23: 98-102.

Sussman, J.L.; Harel, M.; Frolow, F.; Oefner, C.; Goldman, A. et al. (1991). Atomic structure of acetylcholinesterasefrom Torpedo californica: a prototypic acetylcholine-binding protein. Science, 253 (5022): 872-879.

Vilela, A.F.L.; Cardoso, C.L.; Mateo, C. (2019). An immobilized acetylcholinesterase as a test system to screen new inhibitor drugs to treatAlzheimer's disease. Sensors and Actuators B: Chemical, 278: 196-201.

Wiersielis, K.R.; Ceretti, A.; Hall, A.; Famularo, S.T.; Salvatore, M. et al. (2019). Sex differences in corticotropin-releasing factor regulation of medial septum- mediated memory formation. Neurobiology of Stress, 10: 100150.

Zhao, X.; Liu, C.; Qi, Y.; Fang, L.; Luo, J. et al. (2016). Timosaponin B-II ameliorates scopolamine-induced cognition deficits by attenuating acetylcholinesterase activity and brain oxidative damage in mice. Metabolic Brain Disease: 6: 1455-161. 
Submitted: $\quad 22 / 02 / 2020$

Revised: $\quad 07 / 05 / 2020$

Accepted: $\quad 11 / 05 / 2020$

DOI: $\quad 10.48129 /$ kjs.v48i3.9217 